\title{
Lessons Learned from 15 Years of KIMS and 5 Years of ACROSTUDY
}

\author{
Anton Luger ${ }^{a} \quad$ Ulla Feldt-Rasmussen ${ }^{b}$ Roger Abs ${ }^{c}$ Rolf C. Gaillard ${ }^{d}$ \\ Michael Buchfelder ${ }^{e}$ Peter Trainer ${ }^{f}$ Thierry Brue ${ }^{g}$ \\ ${ }^{a}$ Clinical Division of Endocrinology and Metabolism, Medical University of Vienna, Vienna, Austria; \\ ${ }^{b}$ Department of Medical Endocrinology, Rigshospitalet, Copenhagen University, Copenhagen, Denmark; \\ 'Department of Endocrinology, University of Antwerp, Antwerp, Belgium; 'Department of Endocrinology, \\ Diabetes and Metabolism, University Hospital, Lausanne, Switzerland; ${ }^{e}$ Department of Neurosurgery, \\ University of Erlangen-Nürnberg, Erlangen, Germany; ${ }^{f}$ Christie Hospital, University of Manchester, Manchester, UK; \\ gUniversité de la Mediterranée, Marseille, France
}

\section{Key Words}

Acromegaly - Growth hormone deficiency •

Pharmacoepidemiological surveys

\begin{abstract}
Background: Pharmacoepidemiological surveys provide a valuable contribution to the continued monitoring of drugrelated effects in patients with rare disorders. One of the earliest examples of this type of survey is KIGS (Pfizer International Growth Study Database), which has monitored the safety and effectiveness of growth hormone $(\mathrm{GH})$ therapy in GH-deficient children since its inception in 1987. Following closely in the footsteps of KIGS is KIMS (Pfizer International Metabolic Database). As of 2009, KIMS has been collecting data on the long-term safety and clinical outcomes of $\mathrm{GH}$ replacement in $\mathrm{GH}$-deficient adults for 15 years. Approximately 5 years ago, the ACROSTUDY database was established to monitor the long-term safety and effectiveness of pegvisomant in patients with acromegaly. Conclusions: By collecting data on the treatment of relatively rare conditions in routine clinical practice, pharmacoepidemio-
\end{abstract}

logical surveys such as KIMS and ACROSTUDY provide valuable information on the safety and effectiveness of treatment with $\mathrm{GH}$ replacement and pegvisomant in the real world.

Copyright $\odot 2011$ S. Karger AG, Basel

\section{Years of KIMS}

KIMS (Pfizer International Metabolic Database) has collected a wealth of data on the baseline clinical characteristics of adult patients with growth hormone $(\mathrm{GH})$ deficiency and the long-term effects of treatment with GH. Over the years, physicians who have contributed patient data to KIMS have enabled in-depth analyses, leading to publications on a range of topics in many peer-reviewed journals. A recent analysis found that KIMS publications are widely cited in the scientific literature [1]. According to this analysis [1], 36 published KIMS articles were cited 544 times in 125 different journals - impressive figures given that all the articles cited were published between 1998 and 2006. This illustrates the value of collecting de-

\section{KARGER \\ Fax +4161306 1234 \\ E-Mail karger@karger.ch}

www.karger.com
(C) 2011 S. Karger AG, Basel

$1663-2818 / 11 / 0767-0033 \$ 38.00 / 0$

Accessible online at:

www.karger.com/hrp
A. Luger

Department of Medicine III, Medical University of Vienna

Waehringer Guertel 18-20

AT-1090 Vienna (Austria)

Tel. +43 140400 4310, E- Mail anton.luger@meduniwien.ac.at 
mographic and clinical information during routine clinical practice from a large number of adult patients with a relatively rare condition like GH deficiency. KIMS data clearly provide important long-term information complementary to that obtained in randomized, placebocontrolled clinical trials.

\section{Data Available in KIMS}

As of March 2009, KIMS contained information collected from 14,190 adults with GH deficiency from 31 countries. Of the patients enrolled in the KIMS database, 4,740 have now been followed for over 5 years of GH therapy, and there are more than 10 years of follow-up in 1,196 of the patients. In total, 55,849 patient-years of data have been accumulated. The KIMS database contains a wide range of information on these patients, and these data have been the subject of many physician-led analyses.

\section{Clinical Outcomes of GH Replacement}

GH replacement improves the adverse metabolic profile and the impaired quality of life (QoL) associated with $\mathrm{GH}$ deficiency in adults. Analyses of KIMS data have contributed to the widespread acceptance of the benefits of $\mathrm{GH}$ replacement. For example, data on KIMS patients followed longitudinally for 2 years showed that GH therapy significantly reduced mean total and low-density lipoprotein-cholesterol levels, with an accompanying decrease in waist circumference and fat mass [2]. Further, all effects were maintained over 2 years of treatment [2]. These findings confirm the favorable effects of GH therapy on the adverse cardiovascular risk profile associated with GH deficiency.

KIMS analyses have been truly groundbreaking regarding assessments of QoL. In early studies, KIMS data established a relationship between $\mathrm{GH}$ replacement and improved QoL after only 12 months of treatment, which paralleled a decrease in healthcare consumption [3]. KIMS studies have used a disease-specific Quality of Life Assessment of GH Deficiency in Adults (QoLAGHDA). The questionnaire has been validated in several different European populations. Studies in various countries have shown that GH replacement has longterm beneficial effects on QoL [4], with improvements related to the degree of QoL impairment at baseline. Furthermore, in a recent study using KIMS data, QoLAGHDA scores were converted into a format suitable for use in health economic cost-utility analyses $[5,6]$. The large quantity of data available within KIMS has made this possible.
As the number of patients included in the database has grown, KIMS has provided the opportunity to look in greater detail at the various etiologies of GH deficiency and to explore the status of, and interactions between, different hormone axes. Analyses of data from KIMS demonstrate that $\mathrm{GH}$ replacement is effective therapy for most conditions causing GH deficiency. For instance, patients with craniopharyngioma, who generally present with a higher body mass index than patients in other etiological subgroups, showed sustained clinical improvement during GH replacement [7]. Patients with craniopharyngioma responded as well to GH therapy in terms of fat-free mass, lipid levels and QoL as did patients with nonfunctioning pituitary adenoma; they were less likely to lose body fat, presumably reflecting their strong tendency to accumulate fat over time. In another study, KIMS data showed that prior pituitary irradiation did not compromise the beneficial effects of GH replacement therapy [8]. In addition, analyses of KIMS data indicated that adults with isolated GH deficiency experience problems that are qualitatively similar to adults with multiple pituitary hormone deficiencies, and they respond equally well to GH therapy [9]. KIMS data have also confirmed observations that sex steroid and glucocorticoid replacement regimens affect the $\mathrm{GH}$ dose needed to normalize insulin-like growth factor-I (IGF-I) levels [10, 11]. These and other studies of data from KIMS provide invaluable insights into the clinical response of patients with $\mathrm{GH}$ deficiency.

\section{Safety of GH Replacement}

One of the primary aims of KIMS is to monitor the long-term safety of GH replacement in GH-deficient adults. Results of the most recent safety analysis (data as of December 2008) in 13,288 adults followed for over 55,000 patients-years are reassuring [12].

When GH replacement therapy was first approved in adults, there were concerns that the treatment might adversely impact the recurrence of tumors and/or the development of other neoplasms [13, 14]. Based on KIMS data, there is no evidence that GH therapy is associated with an increased incidence of de novo malignancy or intracranial tumor recurrence [12]. The overall recurrence rate of cranial tumors reported in KIMS is comparable to rates reported in the literature for patients not receiving $\mathrm{GH}$ replacement therapy. Likewise, the incidence of other observed neoplasms is similar to expected values within the normal population (standardized mortality ratio 1.03; 95\% CI 0.92-1.15; data on file). 
Adults with hypopituitarism receiving conventional hormone replacement therapy (but not GH replacement) are at increased risk of death from cardiovascular and cerebrovascular disease relative to the normal population $[14,15]$. The mortality rate among KIMS patients receiving GH therapy is similar to that expected in the normal population when matched for age, sex, and country of origin (standardized mortality ratio 1.01; 95\% CI $0.89-1.14$ ) [16]. Furthermore, there is a significant negative association between IGF-I levels during GH treatment and mortality rates, suggesting that GH replacement may have a beneficial effect on the mortality rate in GH-deficient patients. This association is most significant for IGF-I levels and mortality from cardiovascular and cerebrovascular diseases, though longer followup is needed to confirm these findings. Nevertheless, it is clear that KIMS data are proving extremely valuable in the ongoing assessment of the long-term safety of GH treatment.

\section{ACROSTUDY: The First 5 Years}

The ACROSTUDY database has come a long way since enrollment of the first patients in Germany in 2004 [17]. ACROSTUDY now contains data on 792 patients with acromegaly from over 300 centers in 10 countries. There is a total of 2,624 patient-years of data for patients who are being treated with pegvisomant. Capturing this quantity of data over such a relatively short time period is a remarkable achievement. Analyses of data from ACROSTUDY have yielded numerous insights.

Serum IGF-I concentrations are the best marker of the efficacy of pegvisomant in patients with acromegaly [18]. Disappointingly, 5-year data from ACROSTUDY indicate sustained normalization of IGF-I levels is achieved in only $60-70 \%$ of patients receiving pegvisomant, which is markedly less than the $>90 \%$ rate reported in clinical trials $[19,20]$. However, analysis of data regarding the prescribed pegvisomant dosage suggests that the difference in normalization rates between clinical trials and the real world may reflect inadequate dose titration. Interestingly, there was no difference in the normalization rates for IGF-I levels when patients receiving pegvisomant as monotherapy were compared with those receiving pegvisomant in combination with somatostatin analogues. Thus, the ACROSTUDY database is already providing useful information about the effectiveness of pegvisomant in routine clinical practice.

15 Years of KIMS and 5 Years of ACROSTUDY
Safety data have also been reassuring. Of the 276 adverse events reported for patients in ACROSTUDY, 69 (25\%) were considered to be possibly related to pegvisomant treatment - 13 serious and 56 non-serious events. ACROSTUDY also captures follow-up data relating to changes in liver function and tumor volume - both areas of initial concern to treating physicians. In the latest analyses, elevated liver enzyme levels have been reported in 30 patients receiving pegvisomant. However, there is no evidence that they persist after discontinuation of pegvisomant. The mechanism responsible for liver function disturbance remains uncertain.

As of February 2009, ACROSTUDY data show changes in tumor volume in 70 patients. Tumor volumes decreased in 31 patients and increased in 22 patients; a centralized review of magnetic resonance images (MRIs) failed to confirm tumor expansion in 6 patients, and data on tumor size in the remaining 11 patients were contradictory. Clearly, continued collection of safety data is necessary here.

The assessment of changes in pituitary tumor size has been the focus of intensive study in Germany. Physicians involved in ACROSTUDY have developed detailed methodology and techniques for assessing pituitary tumor size based on MRI data, and they have conducted an analysis to confirm reported increases in tumor size in German patients. In the 20 cases reported, investigators found no evidence of an increase in tumor size in 11 patients. Tumor growth following initiation of pegvisomant therapy was confirmed in 4 patients, 3 of whom showed only slight increases in tumor volume. In the remaining 5 patients, tumor growth was either observed prior to the initiation of pegvisomant therapy $(n=3)$ or was related to the withdrawal of somatostatin analogue therapy $(n=2)$. These data suggest that the rate of tumor expansion in patients receiving pegvisomant is similar to that observed in patients receiving somatostatin analogues, where it has been reported that up to $2.2 \%$ of tumors continue to grow [21]. On the basis of this detailed study, any suspected change in tumor volume should be confirmed. Centralized reading of MRI data has now been incorporated into the ACROSTUDY protocol, and physicians are encouraged to submit MRIs for a second opinion on potential changes in tumor volume. Details on how to do this are provided in figure 1.

Given the depth of data already captured in this database, ACROSTUDY is expected to play a key role in the ongoing monitoring of safety and clinical outcomes associated with pegvisomant therapy in patients with acromegaly.

Horm Res Paediatr 2011;76(suppl 1):33-38 


\section{ACROSTUDY}

\section{ACROSTUDY Central MR Reading Instructions}

According to the ACROSTUDY protocol, if there is a change in tumor size after ACROSTUDY enrollment all images should be sent for central evaluation. Such evaluations are offered free of charge to all participating sites and performed by Prof. Dr. med. M. Buchfelder at the Neurochirurgische Klinik der Universität Erlangen-Nürnberg in Erlangen, Germany.

The following points are essential to avoid confusion and to allow a proper interpretation of the MR investigations (MRI).

1. All MRI for evaluation should be sent directly from the ACROSTUDY site to the central evaluation center to prevent Pfizer from accessing patient personal information.

2. Please fill in the ACROSTUDY Central MRI Reading form for each MRI. MRIs and forms should be sent together to the following address:

Prof. Dr. M. Buchfelder,

Tumor Volume Reference Center -

Project ACROSTUDY -,

Neurochirurgische Klinik der

Universität Erlangen-Nürnberg,

Schwabachanlage 6, DE-91054 Erlangen, Germany.

This means that if $2 \mathrm{CD}-\mathrm{ROMs}$ and 3 printed MR films are sent, 5 forms are needed. Please indicate the ACROSTUDY Id/Program Id of the patient on the ACROSTUDY Central MR Reading form, which will be used to identify the report. The central evaluation center is blinded to patient's name and treatment other than Somavert. Patient name will be replaced by the ACROSTUDY Id/Program Id by the Erlangen Center unless it is already done prior to submission.

3. Either CD-ROM data sets or printed images on paper or film may be submitted for re-analysis. Particularly sagittal and coronal sections of T1-weighted images, preferably after contrast application, are appreciated. Please mark clearly the envelope by writing 'ACROSTUDY' so that data and films can be identified as ACROSTUDY materials.

4. To obtain the best possible information on tumor size evolution, as many MRIs as possible should be submitted. Therefore send at least one MRI from before the start of Somavert therapy and as many MRIs as possible after Somavert start. After evaluation, the best possible fit sections of magnification, contrast and grey scale corrected images will be sent back to the investigator together with a short written report. A copy of the report will also be sent to ACROSTUDY Medical Outcomes at Pfizer.

5. Original materials will be returned to the investigators within two weeks. The central evaluation center will only keep the most relevant images blinded for patient name. Should there be any queries, please do not hesitate to contact

Mrs Silke Speck

Neurochirurgische Klinik der

Universität Erlangen-Nürnberg in Erlangen, Germany

Tel. +49 91318534566

E-Mail nch-sekretariat@uk-erlangen.de

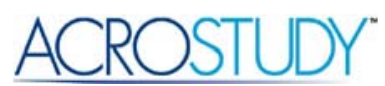

Central MRI Reading

\section{Patient Information}

ACROSTUDY Program ID

Date of Birth $(y / m / d)$ :

\section{Information about the MRI Examination}

Date of the MRI scan $(y / m / d)$ :

Enclosed you find

a CD-ROM containing the MRI examination data (preferred)

MRI films

Printed images

The MRI films have to be resent after being copied

The MRI examination has been performed

before start of SOMAVERT treatment

$\square$ at ACROSTUDY start, the patient commenced Somavert treatment before ACROSTUDY enrollment

as a follow-up examination during SOMAVERT treatment

other:

Local evaluation of the MRI films has shown

a change in pituitary tumor volume

\section{In case of any questions, please contact}

Clinic/Institution:

Name:

Phone/Fax:

Please send the MRI scans together with the completed form to: Prof. Dr. M. Buchfelder

Tumor Volume Reference Center - Project ACROSTUDY Neurochirurgische Klinik der

Universität Erlangen/Nürnberg

Schwabachanlage 6

DE-91054 Erlangen, Germany

Fig. 1. ACROSTUDY instructions and form to obtain central reading of MRIs. 


\section{Conclusions}

Pharmacoepidemiological surveys such as KIMS and ACROSTUDY have a clear role to play in modern medicine. By collecting data on the treatment of relatively rare conditions in routine clinical practice, they provide valuable information on the safety and effectiveness of treatment with GH replacement and pegvisomant in the real world. Important insights have been gained from the many in-depth data analyses already conducted using these databases, and additional hypotheses have been generated that warrant further study. Information gleaned from KIMS and ACROSTUDY ultimately serve to assist the clinician in everyday decision-making. These data are therefore an important addition to the knowledge gained through randomized, placebo-controlled clinical trials.

\section{Disclosure Statement}

A.L. is a consultant to Merck, on advisory committees/review panels for Pfizer, Novo Nordisk, Aventis, Takeda, Bayer, Merck and MSD, a speaker/teacher for Novo Nordisk, Takeda, Bayer, Merck and MSD, performs contracted or funded research for Novo Nordisk and is an investigator in clinical trials sponsored by Novo Nordisk and Aventis. He receives honoraria from Pfizer, Novo Nordisk, Aventis, Takeda, Bayer, Merck and MSD. He received an honorarium from Pfizer in association with his presentation and resulting manuscript for the proceedings for the 41st International Symposium sponsored by Pfizer.

U.F.-R. is on advisory committees/review panels for Pfizer and Genzyme and a speaker/teacher for Pfizer, performs contracted or funded research for Novo Nordisk and Genzyme and is an investigator in clinical trials sponsored by Novo Nordisk. She receives consulting fees from Genzyme and honoraria from Novo
Nordisk and Pfizer. She received an honorarium from Pfizer in association with her presentation and resulting manuscript for the proceedings for the 41st International Symposium sponsored by Pfizer.

R.A. is a speaker/teacher for Pfizer and an investigator in clinical trials sponsored by Pfizer, Novartis and Ipsen. He receives honoraria from Pfizer. He received an honorarium from Pfizer in association with his presentation and resulting manuscript for the proceedings for the 41st International Symposium sponsored by Pfizer.

R.C.G. is on advisory committees/review panels for Pfizer and Lilly and an investigator in clinical trials sponsored by SanofiAventis, Lilly, Novo Nordisk and Novartis. He received an honorarium from Pfizer in association with his presentation and resulting manuscript for the proceedings for the 41st International Symposium sponsored by Pfizer.

M.B. is a speaker/teacher for Pfizer, Novartis and Lilly, on advisory committees/review panels for Pfizer, an investigator in clinical trials sponsored by Pfizer and conducts contracted or funded research for Pfizer. He receives honoraria from Pfizer, Novartis and Lilly. He received an honorarium from Pfizer in association with his presentation and resulting manuscript for the proceedings for the 41st International Symposium sponsored by Pfizer.

P.T. is a speaker/teacher for Pfizer and Novartis, on advisory committees/review panels for Pfizer and Novartis and an investigator in clinical trials sponsored by Pfizer and Novartis. He receives honoraria from Pfizer and Novartis. He received an honorarium from Pfizer in association with his presentation and resulting manuscript for the proceedings for the 41st International Symposium sponsored by Pfizer.

T.B. is a consultant to Pfizer, Novartis and Ipsen, a speaker/ teacher for Pfizer and Merck-Serono, an investigator in clinical trials sponsored by Novartis and Ipsen and conducts contracted or funded research for Pfizer. He received an honorarium from Pfizer in association with his presentation and resulting manuscript for the proceedings for the 41st International Symposium sponsored by Pfizer.

Production logistics including collection of manuscripts, assistance to editors, obtaining reprint permissions, graphic design and layout were provided by CMM Global.

\section{References}

1 Gutierrez LP, Kołtowska-Häggström M, Jonsson PJ, Mattsson AF, Svensson D, Westberg B, Luger A: Registries as a tool in evidence-based medicine: example of KIMS (Pfizer International Metabolic Database). Pharmacoepidemiol Drug Saf 2008;7:90102.

2 Abs R, Feldt-Rasmussen U, Mattsson AF, Monson JP, Bengtsson BÅ, Góth MI, Wilton $\mathrm{P}$, Kołtowska-Häggström M: Determinants of cardiovascular risk in 2,589 hypopituitary GH-deficient adults - a KIMS database analysis. Eur J Endocrinol 2006;155:79-90.
3 Hernberg-Ståhl E, Luger A, Abs R, Bengtsson BÅ, Feldt-Rasmussen U, Wilton P, Westberg B, Monson JP, KIMS International Board on behalf of the KIMS Study Group: Healthcare consumption decreases in parallel with improvements in quality of life during $\mathrm{GH}$ replacement in hypopituitary adults with GH deficiency. J Clin Endocrinol Metab 2001;86:5277-5281.

4 Kołtowska-Häggström M, Mattsson AF, Monson JP, Kind P, Badia X, Casanueva FF, Busschbach J, Koppeschaar HP, Johannsson G: Does long-term GH replacement therapy in hypopituitary adults with GH deficiency normalise quality of life? Eur J Endocrinol 2006;155:109-119.
5 Kołtowska-Häggström M, Kind P, Monson JP, Jonsson B: Growth hormone $(\mathrm{GH})$ replacement in hypopituitary adults with $\mathrm{GH}$ deficiency evaluated by a utility-weighted quality of life index: a precursor to cost-utility analysis. Clin Endocrinol (Oxf) 2008;68: 122-129.

6 Kołtowska-Häggström M, Jonsson B, Isacson D, Bingefors K: Using EQ-5D to derive general population-based utilities for the quality of life assessment of growth hormone deficiency in adults (QoL-AGHDA). Value Health 2007;10:73-81. 
7 Verhelst J, Kendall-Taylor P, Erfurth EM, Price DA, Geffner M, Kołtowska-Häggström M, Jonsson PJ, Wilton P, Abs R: Baseline characteristics and response to 2 years of growth hormone $(\mathrm{GH})$ replacement of hypopituitary patients with $\mathrm{GH}$ deficiency due to adult-onset craniopharyngioma in comparison with patients with nonfunctioning pituitary adenoma: data from KIMS (Pfizer International Metabolic Database). J Clin Endocrinol Metab 2005;90:4636-4643.

8 Maiter D, Abs R, Johannsson G, Scanlon M, Jönsson PJ, Wilton P, Kołtowska-Häggström M: Baseline characteristics and response to GH replacement of hypopituitary patients previously irradiated for pituitary adenoma or craniopharyngioma: data from the Pfizer International Metabolic Database. Eur J Endocrinol 2006;155:253-260.

9 Abs R, Mattsson AF, Bengtsson BÅ, FeldtRasmussen U, Góth MI, KołtowskaHäggström M, Monson JP, Verhelst J, Wilton P, KIMS Study Group: Isolated growth hormone (GH) deficiency in adult patients: baseline clinical characteristics and responses to GH replacement in comparison with hypopituitary patients. A sub-analysis of the KIMS database. Growth Horm IGF Res 2005; 15:349-359.

10 Mah PM, Webster J, Jonsson P, Feldt-Rasmussen U, Kołtowska-Häggström M, Ross $\mathrm{RJ}$ : Estrogen replacement in women of fertile years with hypopituitarism. J Clin Endocrinol Metab 2005;90:5964-5969.
11 Filipsson H, Monson JP, Kołtowska-Häggström M, Mattsson A, Johannsson G: The impact of glucocorticoid replacement regimens on metabolic outcome and comorbidity in hypopituitary patients. J Clin Endocrinol Metab 2006;91:3954-3961.

12 Svensson J, Bengtsson BÅ: Safety of growth hormone replacement therapy in adults; in Feldt-Rasmussen U, Abs R (eds): Growth Hormone Deficiency in Adults: 10 Years of KIMS. Oxford, Oxford PharmaGenesis Ltd., 2004, pp 315-322.

13 Hatrick AG, Boghalo P, Bingham JB, Ayres $A B$, Sönksen PH, Russell-Jones DL: Does GH replacement therapy in adult GH-deficient patients result in recurrence or increase in size of pituitary tumours? Eur J Endocrinol 2002;146:807-811.

14 Rosén T, Bengtsson BÅ: Premature mortality due to cardiovascular disease in hypopituitarism. Lancet 1990;336:285-288.

15 Bülow B, Hagmar L, Mikoczy Z, Nordström $\mathrm{CH}$, Erfurth EM: Increased cerebrovascular mortality in patients with hypopituitarism. Clin Endocrinol (Oxf) 1997;46:75-81.

16 Wilton P, Gaillard R, Saller B, KołtowskaHäggström M, Mattsson A: Cause-specific mortality in patients from the KIMS database and associations with IGF-I standard deviation score (SDS). Growth Horm IGF Res 2008;18(suppl 1):S3.
17 Brue T: ACROSTUDY: status update on 469 patients. Horm Res 2009;71(suppl 1):34-38.

18 Stewart PM: Pegvisomant: an advance in clinical efficacy in acromegaly. Eur J Endocrinol 2003;148(suppl 2):S27-S32.

19 van der Lely AJ, Hutson RK, Trainer PJ, Besser GM, Barkan AL, Katznelson L, Klibanski A, Herman-Bonert V, Melmed S, Vance ML, Freda PU, Stewart PM, Friend KE, Clemmons DR, Johannsson G, Stavrou S, Cook DM, Phillips LS, Strasburger CJ, Hackett S, Zib KA, Davis RJ, Scarlett JA, Thorner MO: Long-term treatment of acromegaly with pegvisomant, a growth hormone receptor antagonist. Lancet 2001;358:1754-1759.

20 Trainer PJ, Drake WM, Katznelson L, Freda PU, Herman-Bonert V, van der Lely AJ, Dimaraki EV, Stewart PM, Friend KE, Vance ML, Besser GM, Scarlett JA, Thorner MO, Parkinson C, Klibanski A, Powell JS, Barkan AL, Sheppard MC, Malsonado M, Rose DR, Clemmons DR, Johannsson G, Bengtsson BA, Stavrou S, Kleinberg DL, Cook DM, Phillips LS, Bidlingmaier M, Strasburger CJ, Hackett S, Zib K, Bennett WF, Davis RJ: Treatment of acromegaly with the growth hormone-receptor antagonist pegvisomant. N Engl J Med 2000;342:1171-1177.

21 Besser GM, Burman P, Daly AF: Predictors and rates of treatment-resistant tumor growth in acromegaly. Eur J Endocrinol 2005;153:187-193. 